\title{
45,X/46,XY mosaicism: a cause of short stature in males
}

\author{
Alexandra Efthymiadou, ${ }^{1}$ Eunice G. Stefanou, ${ }^{2}$ Dionisios Chrysis ${ }^{1}$ \\ ${ }^{1}$ Division of Pediatric Endocrinology, ${ }^{2}$ Laboratory of Medical Genetics, Department of Pediatrics, University of Patras, \\ Patras, Greece
}

\begin{abstract}
45,X/46,XY mosaicism is associated with a broad spectrum of phenotypes ranging from apparently normal male development to individuals with incomplete sexual differentiation and clinical signs of Turner syndrome in both males and females. The most common presentation among individuals with a 45,X/46,XY karyotype is sexual ambiguity, accounting for approximately $60 \%$ of cases, while the least common category of $45, X / 46, X Y$ patients consists of those with bilaterally descended testes, found in $11-12 \%$. We report on two patients with an apparently normal male phenotype and $45, \mathrm{X} / \mathbf{4 6}, \mathrm{XY}$ mosaicism who were diagnosed postnatally because of short stature. Both of these boys presented at the age of 15 years with short stature, minor Turner-like stigmata, normal male external genitalia and spontaneous pubertal development. One of them had coarctaction of the aorta with bicuspid aortic valve, an uncommon clinical feature in boys with mosaicism. The same patient underwent a trial of GH replacement therapy with poor response and his sperm analysis revealed azoospermia. Like our patients, most mosaic 45, X/46,XY children with bilateral scrotal testes go unrecognised at birth and throughout childhood unless they have somatic features of Turner syndrome or significant growth retardation. We recommend that boys with otherwise unexplained short stature, being short for their families, should be karyotyped routinely as is recommended in short-stature girls. In addition, boys with $45, X / 46, X Y$ mosaicism require a thorough clinical evaluation similar to that performed in girls with Turner syndrome and must be routinely followed up for their potential to respond favorably to GH treatment and for late onset abnormalities, such as infertility and gonadal tumors.
\end{abstract}

Key words: 45,X/46,XY mosaicism, Male, Short stature

\section{CASE REPORT 1}

The first patient presented at the age of 15 years and 2 months with short stature. The patient's

\footnotetext{
Address for correspondence:

Dr Alexandra Efthymiadou, Division of Pediatric

Endocrinology, Department of Pediatrics, University Hospital of Patras, 26504 Rion Patras, Greece, Tel.: +302610999546,

Fax: +302610994711, e-mail: eythymiadou@upatras.gr

Received 19-01-12, Revised 12-03-12, Accepted 10-04-12
}

height was $150.5 \mathrm{~cm}(-2.6 \mathrm{SD})$, sitting height was $82 \mathrm{~cm}(-1.77 \mathrm{SD})$, his weight was $55.1 \mathrm{Kg}$ and his BMI was 24.3 (+1.65 SD). Mid-parental height (MPH) was $187 \mathrm{~cm}(+1.42 \mathrm{SD})$, thus the patient was $36.5 \mathrm{~cm}$ shorter than his target height. Pregnancy and neonatal history was unremarkable and his birth weight was $2900 \mathrm{gr}$. From his past medical history a severe cardiac malformation with coarctaction of the aorta and bicuspid aortic valve was discovered and oper- 
ated on at 12 years of age. Non-verbal learning disabilities, mainly in mathematics, were reported and a tendency for low self-esteem. He was supported with an individualized education plan tailored to his school requirements.

On physical examination he had scoliosis, hallus valgus, mild nail dysplasia, high arched palate and Turner-like appearance (broad chest with widely spaced nipples). The boy had normal male phenotype and normal male external genitalia, marked pubic hair (Tanner stage V) and enlarged testes with testicular volume $15 \mathrm{ml}$ bilaterally, with soft consistency. Renal and testicular ultrasound were normal. Hearing testing was normal.

Laboratory analysis demonstrated basal levels of FSH 10,7mIU/ml, LH 10,2mIU/ml, Testosterone $471.5 \mathrm{ng} / \mathrm{dl}$, Estradiol 15pg/ml,Cortisol $16.3 \mu \mathrm{g} /$ dl, Prolactin 14.2ng/ml, DHEAS 178.6 $\mu \mathrm{g} / \mathrm{dl}, \Delta 4-$ androstenedione $2.30 \mathrm{ng} / \mathrm{ml}$, 17-hydroxy progesterone $1.90 \mathrm{ng} / \mathrm{ml}$, all within the normal range. Levels of carcinoembryonic antigen (CEA) $0.85 \mathrm{ng} / \mathrm{ml}$, afetoprotein $3.36 \mathrm{ng} / \mathrm{ml}$ and $\beta$-hCG $0.01 \mathrm{IU} / \mathrm{ml}$ were also normal. Bone age was estimated at 14 years 6 months. Laboratory evaluation showed normal levels of insulin-like growth factor 1 (IGF-I $224 \mathrm{mg} / \mathrm{dl}$ ). A GnRH test revealed a normal pubertal pattern (FSH level of 4.2, 9.6, 17.3, and $20.1 \mathrm{mIU} / \mathrm{ml}$ and LH level of $<0.1,6.1,41.8$, and $42.8 \mathrm{mIU} / \mathrm{ml}$ at $0,15,30,45$ minutes, respectively). Sperm analysis showed azoospermia. Cytogenetic analysis of peripheral blood revealed a karyotype with mos 45,X [5]/46,XY [65].

Because of the diagnosis of $45, \mathrm{X} / 46, \mathrm{XY}$ mosaicism, treatment with growth hormone $(\mathrm{GH})$ was initiated at the age of 15 years and 9 months at a dose of 0.025 $\mathrm{mg} / \mathrm{kg}$ per day. During the first 4 months of GH replacement the patient's body height increased only $1.8 \mathrm{~cm}$, bone age was advanced at 16 years and, based on the poor response, a decision to discontinue $\mathrm{GH}$ replacement therapy was made.

\section{CASE REPORT 2}

The second patient, a 15 year and one month old male, was short in stature and severely obese. The patient's height was $141.5 \mathrm{~cm}(-3.55 \mathrm{SD})$, sitting height was $78.2 \mathrm{~cm}(-2.52 \mathrm{SD})$, his weight was $80.2 \mathrm{Kg}$ and his BMI was 40.1 (+3.64 SD). Mid-parental height (MPH) was $179 \mathrm{~cm}(+0.9 \mathrm{SD})$, thus the patient was $37.5 \mathrm{~cm}$ shorter than his target height. Past medical history, including pregnancy and neonatal history, was unremarkable and his birth weight was 3300gr. Our second patient also had non-verbal learning disabilities and was supported with an individualized education plan tailored to his school requirements. On physical examination he had mild dysmorphic features, with mild nail dysplasia, low posterior hairline, inverted nipples, borderline short fourth metacarpal and cubitus valgus. The boy had normal male external genitalia, no pubic hair (Tanner stage I) and testicular volume was $10 \mathrm{ml}$ (right) and $6 \mathrm{ml}$ (left). Echocardiography and renal sonography revealed no abnormalities. Laboratory analysis revealed basal levels of FSH $3.8 \mathrm{mIU} /$ $\mathrm{ml}, \mathrm{LH} 2.8 \mathrm{mIU} / \mathrm{ml}$, Testosterone 45.46ng/dl, Cortisol $5.6 \mu \mathrm{g} / \mathrm{dl}$, Prolactin 5.9ng/ml, DHEAS 206 $\mathrm{g} / \mathrm{dl}$, all within the normal range. Levels of carcinoembryonic antigen (CEA) $1.05 \mathrm{ng} / \mathrm{ml}$, a-fetoprotein $2.17 \mathrm{ng} / \mathrm{ml}$ and $\beta$-hCG $<0.01 \mathrm{IU} / \mathrm{ml}$ were also normal.

Bone age was delayed at 13 years 6 months and laboratory evaluation showed low levels of insulin-like growth factor 1 (IGF- I 59mg/dl). GH provocative testing gave laboratory evidence of GH deficiency $(0.64 \mathrm{ng} / \mathrm{ml}$ and $1.0 \mathrm{ng} / \mathrm{ml}$ maximum $\mathrm{GH}$ rise after combined betaxolole/clonidine stimulation and LDopa stimulation, normal $>10 \mathrm{ng} / \mathrm{ml}$ ). Cytogenetic analysis of peripheral blood revealed a karyotype with mos 45,X [7]/46,XY [43].

Because of the diagnosis of $45, \mathrm{X} / 46, \mathrm{XY}$ mosaicism, treatment with growth hormone $(\mathrm{GH})$ was initiated at the age of 15 years and 8 months at a dose of 0.018 $\mathrm{mg} / \mathrm{kg}$ per day.

\section{DISCUSSION}

45,X/46,XY children present as Turner-like syndrome having bilateral streak gonads with mullerian structures and TS stigmata, as mixed gonadal dysgenesis with a unilateral testis, a contralateral streak gonad and mullerian structures, as males having bilateral testes (any combination of dysgenetic or normal testes) but with mullerian structures and signs of decreased virilization, or as normal males having bilaterally descended testes and normal male genitalia. $^{1-4}$ 
45, $\mathrm{X} / 46, \mathrm{XY}$ mosaicism is considered a postzygotic mitotic error. Loss of the Y chromosome by 'nondisjunction' after normal disomic fertilization leads to the $45, \mathrm{X}$ cell line. If the error ( $\mathrm{Y}$ loss) occurs in early postzygotic cell division, more cells and hence tissues will be affected. Generally, it is a random event that can take place at any time of the embryo development and can affect one or several tissues. The number and distribution of the $45, \mathrm{X}$ cells differs amongst patients, thus producing a spectrum of phenotypic features.

The most common presentation for individuals with a 45,X/46,XY karyotype is sexual ambiguity, accounting for $\sim 60 \%$, and the least common category of $45, \mathrm{X} / 46, \mathrm{XY}$ patients consists of those with bilaterally descended testes, found in $11-12 \% .^{3}$ The true incidence of a 45,X/46,XY karyotype in males with bilaterally descended testes is unknown.

Like our patients, most mosaic 45,X/46,XY children with bilateral scrotal testes go unrecognised at birth and throughout childhood because they usually display minor dysmorphic features of Turner syndrome. The most striking feature of these patients is the unexplained significantly short stature, which raises the suspicion of the diagnosis. According to the literature, all of these boys who have reached adult height have had short stature relative to midparental height (MPH) and only few of them had physical stigmata of Turner syndrome. ${ }^{1,3-7}$ Both of our patients had minor dysmorphic features of TS, mainly unremarkable unless associated with the extremely short stature.

Our first patient had coarctaction of the aorta with bicuspid aortic valve, a very characteristic cardiac anomaly in girls with Turner syndrome. However, in boys with $45, \mathrm{X} / 46, \mathrm{XY}$ karyotype, this is a unique finding, as the review of the literature identifies only one mosaic 45,X/46, XY male patient with aortic coarctation, reported by Telvi et al. ${ }^{3}$ Additionally, both of our patients had learning difficulties, another rare finding in boys with 45,X/46,XY karyotype. Generally, the phenotype of our patient confirms the finding that both physical stigmata of TS and congenital anomalies known to be associated with TS (including congenital cardiac and renal anomalies, recurrent otitis media, hearing defects and visual defects) are more predominant in $\mathrm{X} / \mathrm{XY}$ female children compared to $\mathrm{X} / \mathrm{XY}$ male children. ${ }^{4}$ On the other hand, the extremely rare cardiac anomaly and uncommon learning difficulties found in our patients argues for the phenotypic variability of $45, \mathrm{X} / 46, \mathrm{XY}$ mosaicism, partly explained by the relative distribution of $45 \mathrm{X}$ and 46XY cell lines in different organ-systems. This justifies a thorough clinical evaluation of males with a 45,X/46,XY karyotype similar to that performed in Turner syndrome, including evaluation of cardiac, renal and autoimmune conditions, recurrent otitis media, hearing deficit, ophthalmological deficit, learning disability and behavioral evaluation.

A wide spectrum of abnormal gonadal development including gonadal dysgenesis, infertility, low testosterone level and azoospermia may occur in patients presenting with $45, \mathrm{X} / 46, \mathrm{XY}$ mosaicism as well as an apparently normal male phenotype, which can probably be explained by the predominance of the $45, \mathrm{X}$ or $46, \mathrm{XY}$ cell lines in the gonads. ${ }^{1,3}$ Our patients had normal development of male internal and external genitalia, which indicates sufficient secretion of fetal testosterone. They both went spontaneously into a fairly normal puberty, which happens in most mosaic $45, \mathrm{X} / 46, \mathrm{XY}$ boys. Leydig cell function is at least partially preserved in $45, \mathrm{X} / 46, \mathrm{XY}$ males and often allows spontaneous pubertal development. But later on in adulthood, these patients usually develop infertility because of azoospermia or oligospermia, and elevated gonadotropins. ${ }^{4,7,8}$ Our first patient had azoospermia with elevated gonadotropins, which are clearly signs of primary gonadal failure.

According to the literature, men with the 45,X/46, XY karyotype are at increased risk for germcell neoplasia of the gonads, especially gonadoblastoma and carcinoma in situ. Tumor risk is significantly higher in patients with marked genital ambiguity as compared to patients with mild undervirilisation or with a female phenotype. ${ }^{1,9,10}$ There is not an exact prediction of tumor risk in normal males with $45, \mathrm{X} / 46, \mathrm{XY}$ constitution, but based on the study of Cools et al, the risk is low because the clinical picture of a normal external masculinisation score and bilaterally descended testes suggests a (close to) normal testicular differentiation and maturation process. ${ }^{9}$ Although our patients belong to the lower tumor risk category, close follow-up for development 
of gonadal tumors is mandatory, including physical examination and laboratory investigation with ultrasonography and serum tumor markers. The possibility of testicular biopsy after puberty should be strongly considered in 45,X/46,XY males with cryptorchism and/or hypospadias. ${ }^{9,10}$

The growth pattern of 45,X/46,XY female and male children recently described by Tosson et al. revealed growth deceleration at the time of puberty and adult height compromised relative to mid-parental height. ${ }^{7}$ Early GH treatment should be considered to be part of the management of short stature in 45,X/46,XY male children because, like girls with Turner syndrome, a good linear growth response to $\mathrm{GH}$ therapy was observed in these boys who started GH therapy early in life.$^{5-7}$ Similar to other reports, laboratory evaluation in our first patient showed normal levels of IGF-I, making GH deficiency unlikely., In accordance with the current guidelines of $\mathrm{GH}$ treatment in 45,X/46,XY male children, we offered him a trial of GH therapy, but unfortunately he had a poor response. GH treatment may have started too late to exert a significant influence on the final height of our patient. On the other hand, laboratory evaluation in our second patient revealed GH deficiency (low levels of IGF-I, abnormal GH provocative tests) and, taking into account the diagnosis of 45,X/46,XY mosaicism, GH replacement therapy was initiated.

In conclusion, $45, \mathrm{X} / 46, \mathrm{XY}$ mosaicism is underdiagnosed or late-diagnosed in phenotypic males with short stature. We recommend that boys with otherwise unexplained short stature, being short for their families, should be karyotyped routinely, as is recommended in short-stature girls. In addition, boys with $45, \mathrm{X} / 46, \mathrm{XY}$ mosaicism require a thorough clinical evaluation similar to that performed in girls with Turner syndrome and must be routinely followed up for their potential to respond favorably to $\mathrm{GH}$ treatment and for late onset abnormalities, such as infertility and gonadal tumors.

\section{REFERENCES}

1. Knudtzon J, Aarskog D, 1987 45,X/46,XY mosaicism: a clinical review and report of ten cases. Eur J Pediatr 146: 266-271.

2. Rosenburg C, Frota-Pessoa O, Vianna-Morgante AM, Chu TH, 1987 Phenotypic spectrum of 45,X/46,XY individuals. Am J Med Genet 27: 553-559.

3. Telvi L, Lebbar A, Del Pino O, Barbet JP, Chaussain JL, 1999 45,X/46,XY mosaicism: report of 27 cases. Pediatrics 104: 304-308.

4. Tosson H, Rose SR, Gartner LA, 2011 Description of children with 45,X/46,XY karyotype. Eur J Pediatr 171: 521-529.

5. Lee C-F, Su P-H, Chen S-J, Yang K-C, Lin L-L, 2006 Short stature in patients with 45,X/46,XY mosaicism: report of three cases. Acta Paediatr Tw 47: 312-316.

6. Richter-Unruh A, Knauer-Fischer S, Kaspers S, Albrecht B, Gillessen-Kaesbach G, Hauffa BP, 2004 Short stature in children with an apparently normal male phenotype can be caused by 45,X/46,XY mosaicism and is susceptible to growth hormone treatment. Eur J Pediatr 163: 251-256.

7. Tosson H, Rose SR, Gartner L, 2010 Children with 45,X/46,XY karyotype from birth to adult height. Horm Res Paediatr 74: 190-200.

8. Layman LC, Tho SPT, Clark AD, Kulharya A, McDonough PG, 2009 Phenotypic spectrum of 45,X/46,XY males with ring $Y$ chromosome and bilaterally descended testes. Fertil Steril 91: 791-797.

9. Cools M, Pleskacova J, Stoop H, et al, 2011 Gonadal pathology and tumor risk in relation to clinical characteristics in patients with 45,X/46,XY mosaicism. J Clin Endocrinol Metab 96: E1171-E1180.

10. Müller J, Ritzén EM, Ivarsson S-A, Rajpert-De Meyts E, Norjavaara E, Skakkebæk NE, 1999 Management of males with 45,X/46,XY gonadal dysgenesis. Horm Res 52: 11-14. 